Original Article

\title{
Profile picture of risk factors for breast cancer among community women of Udupi, Karnataka
}

\author{
Arkierupaia Shadap \\ Lecturer, Sikkim M anipal College of Nursing, Sikkim M anipal University. \\ *Corresponding Author : Arkierupaia Shadap, Lecturer, Sikkim M anipal College of Nursing, Sikkim M anipal University, \\ Mobile : +918116213637 E-mail : arkie_ro@rediffmail.com, shadaparkierupaia@gmail.com
}

$\begin{array}{ll}\text { Received } & : 20.06 .2016 \\ \text { Review Completed } & : 19.10 .2016 \\ \text { Accepted } & : 04.11 .2016\end{array}$

Keywords : risk factors, breast cancer.

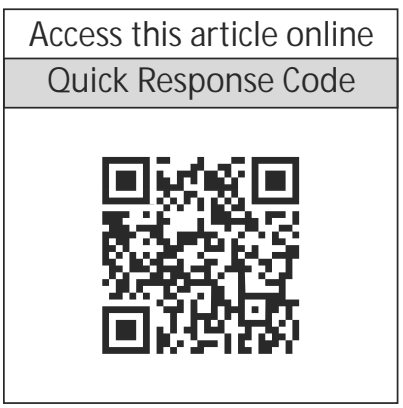

\begin{abstract}
Globally, breast cancer is considered to be one amongst the most commonly cancer. In India, it is considered to be the second cancer disease among women with most of the affected population is in the urban areas. Breast cancer is seen mostly after the age of 40 years. According to the Cancer fact 2012, breast cancer is now seen to be among women aged from 35 years above.
\end{abstract}

M aterials and methods: The study was a descriptive survey study to assess the numbers of risk factors for breast cancer among the 320 community women who were willing to participate in the study. A validated structured questionnaire was given to the subjects after taking consent.

Results: The study finding shows that out of 320 women surveyed,252 (78.75\%) belonged to "with risk" category and 68 (21.25\%) belonged to "No risk" category for risk factors of breast cancer. The risk factorsfor breast cancer detected among these 252 who belonged to 'with risk' were, majority $24.4 \%$ had menarche at the age of $\leq 12$ years, none had the personal history of breast cancer and $0.3 \%$ had the history of first-degree relative sister diagnosed with breast cancer. There were $44.7 \%$ women who first had their delivery at the age of $\geq 30$ years and above. $16.9 \%$ did not give breast feeding; none had the history of biopsy, 3.8\% had the history of taking oral contraceptives of 5 years period and none had the history of takingalcohol in their life.

Conclusion: The study concluded that making the community women aware through health educations, distributing pamphlets and organizing programmes on breast cancer and the risk factors will motivate them to attend the health care services for better treatment. Better treatment will further enhance the morbidity and mortality rate among the community women.

\section{Introduction}

Breast development occurs in distinct stages throughout a woman's life, first before birth, again at puberty, during the childbearing years, menstruation and when a woman reaches menopause. Once ovulation and menstruation begin, the maturing of the breasts begins and continues to grow and mature ${ }^{[1]}$.

As age advanced there are some changes in woman's breast which are normal, but some woman may have changes like lump which are tender and non-tender, abnormal discharge from the breast, ulceration, redness; these are all the early pathological changes ${ }^{[2]}$.

Amin and Mulhim at Saudi 2009 in their study found that $56 \%$ women are unaware of these changes and some of them are reluctant to go for check-up due to many reasons such as; lack of knowledge, shyness, fears and delay in the treatment leads to complications and death ${ }^{[3]}$.

According to India statistics, the number of new breast cancer cases is about 115,000 per year and this is expected to rise to 250,000 new cases per year by 2015 . If discovered early breast cancer can usually be cured; however, early detection through screening is the only way to reduce mortality ${ }^{[4]}$. The most common screening for the early detection is breast self-examination and mammogram. It has been shown that it reduced the breast cancer mortality by $30 \%$ in women aged 50 and older ${ }^{[5]}$. Although the benefit of mammography screening among women aged 40-49 is still under debate. Despite the fact that rates of screening 
mammography have increased over the last several years, many women do not routinely obtained mammograms, and it is estimated that only $70 \%$ of women aged 40 and older had a mammogram within the past 2 years ${ }^{[6]}$.

With the total population of 52,850,562 Karnataka has 1.5 lakhs cancer cases and about 35,000 new cases are added. Incidence of breast cancer in Bangalore increased from $14.5 \%$ in 1990 to $23.5 \%$ in 2005 . Cases of breast cancer among younger age group have increased by $15-20 \%$. It indicates each year, 1, 82,000 women are diagnosed with breast cancer and 43,300 die. The IT capital of India accounts for $26.3 \%$ of breast cancer case. $54 \%$ of women with breast cancer were in the age group of $25-50^{[7]}$.

According to Cancer facts and figures 2005, many studies show that women lack knowledge on breast cancer, unaware of its risk factors and low utilization of the screening test which ${ }^{[8]}$. Women in any age are at risk of breast cancer, as nobody knows the exact cause of breast cancer. Although various possibilities can trigger the breast cancer, but most positive way to reduce the breast cancer risk is to maintain a good breast health. Breast cancer is one of the most frequent cancers among women in both developed and developing countries. The total number of new cases of breast cancer diagnosed annually in the world exceeds one million. It has been observed that breast cancer has been increasing in its onset in the Karnataka with $25 \%$ of the cancer is breast cancer ${ }^{[7]}$.

Studies related to risk factors for breast cancer are still very less in states like Karnataka which is one of the need to conduct this study in selected villages of Udupi taluk, Karnataka one of the largest state in India. This study will also be designed so as to assess the awareness of the community people about breast cancer and its risk factors for early detection of breast cancer.

\section{Material and methods}

The objective of the study was to find out the profile picture of the risk factors for breast cancer among the 320 community women aged 35years and above.The study applied a descriptive survey using the convenience sampling technique. The validated structured risk factors questionnaire was used for data collection after taking prior permission from the Dean, MCON, ethical community, head of villages and participants. Pretesting, reliability and pilot study was done before the final data collection.

\section{Results}

The study finding shows that $42.1 \%$ were within the age group of 35- 44 years, $85.9 \%$ are married women and $92.5 \%$ belonged to Hindu religion. Majority $45.3 \%$ had primary education, $59.4 \%$ were housewife and $59.4 \%$ have a monthly family income of Rs3001-5000. Out of 320 women, $87.5 \%$ have heard about breast cancer and $42.8 \%$ obtained the source of information from the health personnel.

Figure 1 shows that out of 320 women surveyed,252 (78.75\%) belonged to "with risk" category and 68 (21.25\%) belonged to "No risk" category for breast cancer. The pie diagram showing percentage of risk category for breast canceramong women

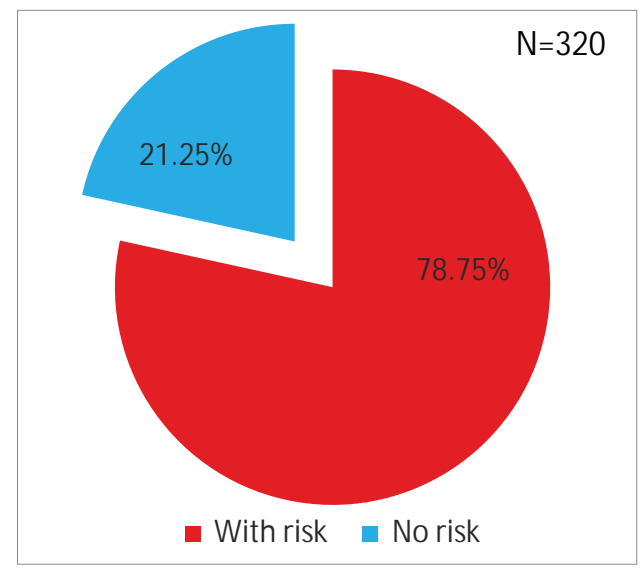

Figure 1 : Pie diagram of women "With risk" category and "No risk" category for breast cancer.

Table 1 : shows the profile picture in frequency and percentage distribution of risk factors for breast cancer

$(\mathrm{N}=\mathbf{2 5 2})$

\begin{tabular}{|l|c|c|}
\hline $\begin{array}{l}\text { Risk factors for breast cancer } \\
\text { with Risk }\end{array}$ & Frequency & Percentage (\%) \\
\hline $\begin{array}{l}\text { 1. Age of the woman at } \\
\text { menarche is } \leq 12 \text { years }\end{array}$ & 77 & 30.55 \\
\hline $\begin{array}{l}\text { 2. Woman have a personal } \\
\text { history of breast cancer }\end{array}$ & 0 & 0 \\
\hline
\end{tabular}




\begin{tabular}{|l|c|c|}
\hline $\begin{array}{l}\text { Risk factors for breast cancer } \\
\text { with Risk }\end{array}$ & Frequency & Percentage (\%) \\
\hline $\begin{array}{l}\text { 3. Woman have the history of } \\
\text { any first degree relatives; } \\
\text { Mother, sisters and daughter } \\
\text { with breast cancer }\end{array}$ & 1 & 0.39 \\
\hline $\begin{array}{l}\text { 4. Age of the woman at first full } \\
\text { term delivery is } \geq 30 \text { years }\end{array}$ & 140 & 55.55 \\
\hline $\begin{array}{l}\text { 5. Woman breast feed the } \\
\text { baby for <1year }\end{array}$ & 148 & 58.73 \\
\hline $\begin{array}{l}\text { 6. Woman ever had a } \\
\text { breast biopsy }\end{array}$ & 0 & 0 \\
\hline $\begin{array}{l}\text { 7. Woman have the history of oral } \\
\text { contraceptives used }>5 y e a r\end{array}$ & 12 & 4.76 \\
\hline $\begin{array}{l}\text { 8. Woman consumed } \\
\text { alcohol(drink of 24g) in a day }\end{array}$ & 0 & 0 \\
\hline
\end{tabular}

The study concluded that majority of the community married women had their first delivery at the age of $\geq 30$ years. With majority have heard about breast cancer, still there are some who are not aware of the risk factors for breast. So, we the health care professionals should teach them and make them aware about the risk factors. Making

\section{References}

1. http://www.hopkinsmedicine.org/healthlibrary/conditions/adult/ breast_health/normal_breast_development_and_changes_85,P001 $51 /$

2. http://canceraustralia.nbocc.org.au/breast-cancer/awareness / breast-changes

3. Amin Tarek, Mulhim Al, M eqihwi Abdullah. Breast cancer knowledge, risk factors and screening among adult Saudi women in a primary health care setting. Asian Pacific Journal of Cancer Prevention.2009; vol 10:pg 133-138

4. Tang TS, Solomon LJ, McCracken LM. Cultural barriers to mammography, clinical breast exam, and breast self-exam among Chinese-American women 60 and older. Prev Med. 2000 Nov;vol 31(5):pg575-83. http://www.ncbi.nlm.nih.gov/pubmed

5. American Cancer Society. Cancer Facts and Figures 2005. http://www.cancer.org

6. Swan J, Breen N, Coates RJ, Rimer BK, Lee NC. Progress in cancer screening practices in the United States: National Health Interview Survey. Cancer 2003; vol 97: pg 1528 - 1540

7. http:// www. The hindu.com/todays- paper/ tp-national/ tpKarnataka/article 3701640.ece.

8. Sulik. National Breast Cancer Awareness Month : Breast Cancer Action. 2010: them aware through health educations, distributing pamphlets and organizing programmes on breast cancer and the risk factors will motivate them to attend the health care services for better treatment. This will further enhance the morbidity and mortality rate among the communitywomen.

\section{Discussion}

The finding of present study was supported by a study was done by Pakseresht S, et al; on "Identification of risk factors with breast cancer among women" in Delhi (2006).A total of 115 women were included in this study aged ranged from 25 to 80 years, 79 (68.7\%) were Hindus, 111 (96.5\%) were housewives and family income less than rupees 460 per capita/month. The study revealed that $74(64.3 \%)$ had breast fed at most three children, 92 (79.8\%) had parity of at least four, 112 (97.4\%) did not use oral contraceptives and $112(96.6 \%)$ did not have any history of breast cancer in the family and no one reported to be drinking. 